\title{
Lack of association between IL-10 -1082G/A polymorphism and chronic periodontal disease in adults
}

\author{
R. Hannum ${ }^{1,2}$, F.R. Godoy ${ }^{1}$, A.S. da Cruz ${ }^{1,3}$, T.C. Vieira ${ }^{1,5}$, L.B. Minasi ${ }^{1,2}$, \\ D. de M. e Silva ${ }^{1,6}$, C.C. da Silva $a^{1,2,3,4,5}$ and A.D. da Cruz ${ }^{1,2,3,4,5}$ \\ ${ }^{1}$ Núcleo de Pesquisas Replicon, Departamento de Biologia, \\ Pontifícia Universidade Católica de Goiás, Goiânia, GO, Brasil \\ ${ }^{2}$ Programa de Pós-Graduação em Genética, \\ Pontifícia Universidade Católica de Goiás, Goiânia, GO, Brasil \\ ${ }^{3}$ Programa de Pós-Graduação em Biologia Celular e Molecular, \\ Universidade Federal de Goiás, Goiânia, GO, Brasil \\ 4Programa de Pós-Graduação em Biotecnologia e Biodiversidade, \\ Universidade de Brasília, Brasília, DF, Brasil \\ ${ }^{5}$ Laboratório de Citogenética Humana e Genética Molecular, \\ Secretaria do Estado da Saúde de Goiás, Goiânia, GO, Brasil \\ ${ }^{6}$ Programa de Pós-Graduação em Genética e Biologia Molecular, \\ Laboratório de Genética e Biodiversidade, Universidade Federal de Goiás, \\ Goiânia, GO, Brasil \\ Corresponding author: L.B. Minasi \\ E-mail: minasilb@gmail.com
}

Genet. Mol. Res. 14 (4): 17828-17833 (2015)

Received August 17, 2015

Accepted October 23, 2015

Published December 22, 2015

DOI http://dx.doi.org/10.4238/2015.December.22.7

ABSTRACT. Because of the complex interaction between periodontal pathogens and the host defense system, periodontitis is considered an inflammatory disorder of bacterial etiology that results in periodontal tissue damage. Genetic mechanisms may interfere with the gene expression of important inflammation mediators, modulating the immunologic 
response of an individual. In this study, we evaluated the single nucleotide polymorphism -1082G/A in the promoter region of interleukin-10 gene and its relationship with periodontal disease in Central Brazil. We included 36 cases classified according to disease severity (mild, moderate, or severe) and 30 controls. The allelic distribution of the cases was 16 (44\%) AG, followed by $13(36 \%)$ GG and $7(20 \%)$ with the genotype AA. In the control group, $13(43 \%)$ presented the genotype AG, $12(40 \%)$ GG and $5(17 \%)$ were classified as AA. The populations examined were in Hardy-Weinberg equilibrium. Analysis of allelic and genotypic frequencies revealed no casual relationship with the presence of genotype $G$ or $A$ and the development of periodontal disease in adults. The single nucleotide polymorphism -1082G/A of the interleukin-10 gene was not predictive of periodontal disease.

Key words: Inflammation; Interleukin-10; Periodontal disease; Polymorphism

\section{INTRODUCTION}

Periodontal disease is a multifactorial disease of the supporting tissues of the teeth. This disease has a relative high prevalence in the population, and is the leading cause of tooth loss (Zhong et al., 2012). Periodontitis can occur when there is an imbalance between periodontopathogenic bacterial species and the host's defense, which is characterized by exacerbation of inflammatory and immunological reactions against the bacterial biofilm (Andrade et al., 2013). Many studies have attempted to identify genetic polymorphisms in mediators of the immune response, such as those that have been considered to be potential susceptibility factors related to periodontal disease (Kornman et al., 1997; Moreira et al., 2007; Tervonen et al., 2007).

The gene encoding for interleukin (IL)-10 is mapped on chromosome 1q31-q32, in a cluster with closely related interleukin genes, including $I L-19, I L-20$, and $I L-24$. Several promoter polymorphisms have been described in the $I L-10$ gene including the single nucleotide polymorphisms (SNPs) at positions -1082 (G/A), which occurs within a putative E26 transformationspecific transcription factor-binding site (Kim et al.,1992).

This cytokine may act on different cell types, by supressing the anti-inflammatory response in various tissues. Moreover, IL-10 is thought to be the main molecule responsible for the response to inflammatory reactions, particularly to inhibit changes mediated by tumor necrosis factor- $\alpha$ (Cullinan et al., 2008; Begue et al., 2011). Its action inhibits the synthesis of proinflammatory cytokines and stimulates the proliferation and differentiation of cells specialized in the body's defense (Begue et al., 2011). IL-10 is also thought to play a role in periodontitis by downregulating the production of monocyte derived proinflammatory cytokines and stimulating protective antibody production (Rousset et al., 1992; de Waal Malefyt et al., 1993). As a result, IL-10 is very important in the immunopathogenesis of chronic inflammatory diseases, such as periodontal disease (Gemmell et al., 1997; Okada and Murakami, 1998). The aim of this study was evaluate the SNP -1082G/A in the promoter region of the $I L-10$ gene and its relation with the periodontal disease in Central Brazilian individuals. 


\section{MATERIAL AND METHODS}

\section{Sample population}

This study included 66 adult Brazilian individuals who lived in the city of Goiânia. The group was divided into 36 cases and 30 controls, grouped in ages ranging from 30-55 years and divided into 5-year periods. Cases were defined as individuals of both genders diagnosed with periodontal disease, regardless of its severity (mild, moderate or severe) clinically identified during physical examination with a millimiter periodontal probe, known as a Michigan O probe (Hu-Friedy, Chicago, IL, USA), with markings of 3,6 , and $8 \mathrm{~mm}$. Controls included healthy individuals, that did not present during the physical examination any clinical signs of periodontal disease with the same distribution by age and gender.

Subjects were instructed as to the character and purpose of the study, and all subjects signed an informed consent. The study protocol was reviewed and approved by the Ethics Committee on Human Research at the Pontifical Catholic University of Goiás under the protocol number 1721/204.

\section{Biological samples and genotyping identification}

In order to identify the polymorphism -1082G/A of IL-101, biological samples were obtained by collecting $5 \mathrm{~mL}$ peripheral blood in EDTA. Genomic DNA was isolated from whole blood using an Invisorb ${ }^{\circledR}$ Spin Blood Mini kit (Invitec Düsseldorfer Landstraße, Germany) according to the manufacturer instructions and stored at $-70^{\circ} \mathrm{C}$ until further processing.

Genotyping was performed by amplification refractory mutation system polymerase chain reaction (ARMS-PCR) (Mellati et al., 2007). Amplification reactions were prepared in a final volume of $50 \mu \mathrm{L}$ containing approximately $100 \mathrm{ng}$ DNA, $7 \mu \mathrm{L}$ Gold STR 10X ${ }^{\circledR}$ Buffer (Promega Corporation, Madison, WI, USA), $2 \mu \mathrm{L} 50 \mathrm{mM} \mathrm{MgCl}$, $5 \cup$ Taq DNA polymerase (Promega Corporation) and a $1-\mu \mathrm{L}$ solution containing the $\mathrm{A}$ or $\mathrm{G}$ sense primers, generic antisense primer, and internal control primers 1 and 2 .

The amplicons produced corresponded to fragments of approximately $258 \mathrm{bp}$. Primers for the internal control of reaction corresponded to an amplicon length of $429 \mathrm{bp}$ of the human growth hormone sequence (Perrey et al., 1999).

The sequences of the primers used in the ARMS-PCR were: generic primer: 5'-CAGTGCCAACTGAGAATTTGG-3', primer A: 5'-ACT ACT AAG GCT TCT TTG GGAA-3', primer G: 5'-CTA CTA AGG CTT CTT TGG GAG-3', internal control primer 1: 5'-GCC TTC CCA ACC ATT CCC TTA-3', and internal control primer 2: 5'-TCA CGG ATT TCT GTT GTG TTT C-3'.

ARMS-PCR was performed using the DNA thermocycler IQ5 ${ }^{\circledR}$ (Bio-Rad, Hercules, CA, USA). Amplicons were obtained using an initial denaturation of $95^{\circ} \mathrm{C}$ for 1 min followed by 10 cycles of denaturation at $95^{\circ} \mathrm{C}$ for $15 \mathrm{~s}$, annealing at $65^{\circ} \mathrm{C}$ for $50 \mathrm{~s}$ and extension at $72^{\circ} \mathrm{C}$ for $40 \mathrm{~s}$ with the A primers, generic primer and internal control primers. Then, 20 cycles were performed for the amplification of primer $\mathrm{B}$ at $95^{\circ} \mathrm{C}$ for $20 \mathrm{~s}$, annealing at $59^{\circ} \mathrm{C}$ for $20 \mathrm{~s}$ and extension at $72^{\circ} \mathrm{C}$ for $20 \mathrm{~s}$. In both thermocycling protocols it was used an extension final step at $72^{\circ} \mathrm{C}$ for $5 \mathrm{~min}$.

The amplicons were visualized by $2 \%$ agarose gel electrophoresis, submitted to an electric field of $10 \mathrm{~V} / \mathrm{cm}$, for one and a half hour. As molecular weight marker, it was used the 100-bp DNA ladder (Invitrogen, USA). The ARMS-PCR products were stained with ethidium bromide $0.5 \mathrm{mg} /$ 
$\mathrm{mL}$ and documented using the Video Documentation System (VDS ${ }^{\circledR}$, Amersham Bioscience, USA), connected to a microcomputer with a capture system and analysis of 21 images (Imagemaster ${ }^{\circledR}$, Amersham Bioscience, USA).

\section{Statistical analysis}

In order to verify the Hardy-Weinberg balance and the expected and observed heterozygosity in the patients from the case group and the control group it was used the Arlequin Program (versão 3.4) (Schneider et al., 2000). It was used an indirect estimator of relative risk (odds ratio), for the search of exposure factors, the genotypic frequencies found in the case group and in the control group were compared. The linear regression test ${ }^{(16)}$, was used to correlate the severity of the periodontal disease and the IL-10 genotype, in the distribution of genotypes of IL-10 in different age groups in the sample group. Significance level was set at $P<0.05$.

\section{RESULTS}

Of the 36 patients analyzed in the case group, $24(67 \%)$ were males and $12(33 \%)$ were females. The mean age of patients was $43 \pm 7.3$ years. The genotypes of the case and control groups after molecular analysis were classified as AA, AG and GG, in the locus of the IL-10 gene. In the control group, 13 (43\%) individuals had the AG genotype, 12 (40\%) had GG and only 5 $(17 \%)$ had AA. The genotype frequencies of case and control groups were compared by the $\chi^{2}$ test, but statistically significant differences were not detected $(P=0.96)$ for the distribution of these frequencies. The frequencies of alleles $A$ and $G$ were also compared by the $\chi^{2}$ test between the case and control groups, but the differences were not statistically significant $(P=0.92)$.

After analysis of the odds ratio, because the lower extreme of the confidence intervals did not exceed 1 and the odds ratio rates were approximately equal to 1 , the 3 genotypes of $I L-10$ were likely not related to periodontal disease in the groups of individuals in this study.

Patients selected for the case group in this study had periodontal disease in degrees classified as mild, moderate and severe. In the age group of $30-35$ years, $5(71 \%)$ patients had mild periodontitis and $2(29 \%)$ had severe condition. In the $35-40$ group, $5(71 \%)$ had moderate periodontal disease. However, in the age group of $40-50$ years, there was a higher prevalence of mild disease, occurring in $100 \%$ of patients aged $40-45$ years and $62.5 \%$ of patients aged 45 50 years. Finally, in the group of 50-55 years, 4 (75\%) patients presented moderate periodontal disease. Analysis of patients with periodontal disease revealed that $22(61 \%)$ had mild periodontitis, $9(25 \%)$ had moderate periodontitis and $5(14 \%)$ had severe periodontitis.

The distribution by gender and its relationship with the severity of periodontal disease showed that of women, $8(67 \%)$ had mild periodontitis, $3(25 \%)$ had moderate periodontitis and only 1 patient ( $8 \%$ ) had severe periodontitis. In men, $14(58 \%)$ had mild periodontitis, $6(25 \%)$ had moderate periodontitis, and $4(16 \%)$ had severe periodontitis. In this case, men were 2-fold more likely to present the severe form of the disease compared to women (16 vs $8 \%$, respectively).

The genotype distribution of $I L-10$ was also associated with the degree of severity of periodontal disease. In the analysis of the group of patients with the mild form, $6(27 \%)$ cases had the genotype AA, $4(50 \%)$ had the genotype AG and $5(23 \%)$ had the genotype GG. In its moderate form, the genotype AG, was the most prevalent and was detected in $6(67 \%)$ cases. In the severe form of the condition, the genotype AG was found in only $1(20 \%)$ case. 
The linear regression test showed that the severity of periodontal disease was not associated with the distribution of genotypes of $I L-10(P=0.61)$, in the different age groups in the sample group.

\section{DISCUSSION}

In periodontitis, the high variability of cytokine levels and the low frequency of this detection may contribute to the presence and/or severity of the disease (Atanasovska-Stojanovska et al., 2012). In the current study, the SNP -1082G/A located in the promoter region of $I L-10$ in patients with periodontal disease and controls was evaluated. The analysis of the frequency of genotypes and allele frequencies revealed no causal relationship between the presence of genotype $G$ or $A$ and the development of periodontal disease in adults.

The most severe cases were observed in subjects greater than 45 years of age, while milder cases were observed in younger age groups. However, no association between the occurrence of the SNP -1082G0/A and periodontal disease was identified. Although more cases were observed among men, no statistically significant association was found in the distribution of genotypes and disease severity in this group. In the present study, the lack of statistical significance in the linear regression test showed that the SNP $-1082 \mathrm{G} / \mathrm{A}$ of the $\mathrm{IL-10}$ gene has no predictive value for periodontal disease. However, the authors reported a higher frequency of the genotype GG in individuals with periodontitis, suggesting that the $\mathrm{G}$ allele plays an important role in the course of periodontal disease (Scarel-Caminaga et al., 2004; Moreira et al., 2007; Tervonen et al., 2007).

Regarding the severity of the disease, we did not observe a higher frequency of the genotype GG in the sick patients. Moreover, the findings of this study are in agreement with those of Kinane and Hard (2003) and Yamazaki et al. (2001), who found no association between the SNP $-1082 \mathrm{G} / \mathrm{A}$ and the occurrence and/or severity of periodontal disease. A large number of studies have found that proinflammatory cytokines are related to the pathogenesis and progression of periodontal disease, thus interventions with the manipulation of anti-inflammatory cytokines have been suggested as adjuvants for treating periodontal disease. However, despite this therapeutic potential, the role of IL-10 in the progression of the periodontal disease has not been thoroughly examined.

The genetic profile of periodontal disease is not well understood. Previous studies suggest a strong association between disease occurrence and individual genetic makeup (Kornman et al., 1997; Folwaczny et al., 2004; Droździk et al., 2006; Mellati et al., 2007). However, this association has not been thoroughly examined (Gasche et al., 2003). Studies of the potential relationship between periodontal disease genetic factors may lead to point to the development of better methods for diagnostics.

\section{CONCLUSIONS}

The results of this study indicate that SNP $-1082 \mathrm{G} / \mathrm{A}$ in the $I L-10$ gene is not involved in the development of periodontal disease. The genetic polymorphism must be further evaluated before it can be used as a diagnostic marker of periodontal disease in adults. In addition, the IL-10 polymorphism showed no prognostic value, which may help healthcare professionals to choose the best course of treatment. The choice of therapy should be based not only on periodontal destruction presented, but also on the risk of developing more severe periodontal problems. 


\section{Conflicts of interest}

The authors declare no conflict of interest.

\section{ACKNOWLEDGMENTS}

The authors thank the participants of this study who agreed to participate and CAPES for funding this publication.

\section{REFERENCES}

Andrade PF, Garlet GP, Silva JS, Fernandes PG, et al. (2013). Adjunct effect of the antimicrobial photodynamic therapy to an association of non-surgical and surgical periodontal treatment in modulation of gene expression: a human study. J. Photochem. Photobiol. B 126: 119-125.

Atanasovska-Stojanovska A, Trajkov D, Popovska M and Spiroski M (2012). IL10 -1082, IL10 -819 and IL10 -592 polymorphisms are associated with chronic periodontitis in a Macedonian population. Hum. Immunol. 73: 753-758.

Ayres M, Ayres Junior M, Ayres DL and Santos AAS (2007). Bioestat. Aplicações estatísticas nas áreas das ciências médicas. 5th edn. Sociedade Civil Mamirauá; MCT, Belém.

Begue B, Verdier J, Rieux-Laucat F, Goulet O, et al. (2011). Defective IL10 signaling defining a subgroup of patients with inflammatory bowel disease. Am. J. Gastroent. 106: 1544-1555

Cullinan MP, Westerman B, Hamlet SM, Palmer JE, et al. (2008). Progression of periodontal disease and interleukin-10 gene polymorphism. J. Periodontal. Res. 43: 328-333.

de Waal Malefyt R, Yssel H and de Vries JE (1993). Direct effects of IL-10 on subsets of human CD4+ T cell clones and resting T cells. Specific inhibition of IL-2 production and proliferation. J. Immunol. 150: 4754-4765.

Droździk A, Kurzawski M, Safronow K and Banach J (2006). Polymorphism in interleukin-1beta gene and the risk of periodontitis in a Polish population. Adv. Med. Sci. 51 (Suppl 1): 13-17.

Folwaczny M, Glas J, Török HP, Fricke K, et al. (2004). The CD14 -159C-to-T promoter polymorphism in periodontal disease. J. Clin. Periodontol. 31: 991-995.

Gasche C, Grundtner P, Zwirn P, Reinisch W, et al. (2003). Novel variants of the IL-10 receptor 1 affect inhibition of monocyte TNF-alpha production. J. Immun. 170: 5578-5582.

Gemmell E, Marshall RI and Seymour GJ (1997). Cytokines and prostaglandins in immune homeostasis and tissue destruction in periodontal disease. Periodontol. 2000 14: 142-143.

Kornman KS, Crane A, Wang HY, di Giovine FS, et al. (1997). The interleukin-1 genotype as a severity factor in adult periodontal disease. J. Clin. Periodontol. 24: 72-77.

Kim JM, Brannan Cl, Copeland NG, Jenkins NA, et al. (1992). Structure of the mouse IL-10 gene and chromosomal localization of the mouse and human genes. J. Immunol. 148: 3618-3623.

Kinane DF and Hart TC (2003). Gene and gene polymorphisms associated with periodontal disease. Crit. Rev. Oral Biol. Med. 14: $430-449$.

Mellati E, Arab HR, Tavakkol-Afshari J, Ebadian AR, et al. (2007). Analysis of -1082 IL-10 gene polymorphism in Iranian patients with generalized aggressive periodontitis. Med. Sci. Monit. 13: CR510-CR514.

Moreira PR, Lima PM, Sathler KO, Imanishi SA, et al. (2007). Interleukin-6 expression and gene polymorphism are associated with severity of periodontal disease in a sample of Brazilian individuals. Clin. Exp. Immunol. 148: 119-126.

Okada H and Murakami S (1998). Cytokine expression in periodontal health and disease. Crit. Rev. Oral Biol. Med. 9: $248-266$.

Perrey C, Turner SJ, Pravica V, Howell WM, et al. (1999). ARMS-PCR methodologies to determine IL-10, TNF-alpha, TNF-beta and TGF-beta 1 gene polymorphisms. Transpl. Immunol. 7: 127-128.

Rousset F, Garcia E, Defrance T, Péronne C, et al. (1992). Interleukin 10 is a potent growth and differentiation factor for activated human B lymphocytes. Proc. Natl. Acad. Sci. U. S. A. 89: 1890-1893.

Scarel-Caminaga RM, Trevilatto PC, Souza AP, Brito RB, et al. (2004). Interleukin 10 gene promoter polymorphisms are associated with chronic periodontitis. J. Clin. Periodontol. 31: 443-448.

Schneider S, Roessli D, Excoffier L and Arlequin V (2000). Softwarefor Population Genetics Data Analysis. Genetics and Biometry Laboratory,University of Geneva, Geneva.

Tervonen T, Raunio T, Knuuttila M and Karttunen R (2007). Polymorphisms in the CD14 and IL-6 genes associated with periodontal disease. J. Clin. Periodontol. 34: 377-383.

Yamazaki K, Tabeta K, Nakajima T, Ohsawa Y, et al. (2001). Interleukin-10 gene promoter polymorphism in Japanese patients with adult and early-onset periodontitis. J. Clin. Periodontol. 28: 828-832.

Zhong Q, Ding C, Wang M, Sun Y, et al. (2012). Interleukin-10 gene polymorphisms and chronic/aggressive periodontitis susceptibility: A meta-analysis based on 14 case-control studies. Cytokine 60: 47-54. 